\title{
Fatores Determinantes da Oferta Turística na Baía de Camamu-BA para o Planejamento do Turismo e Desenvolvimento Local
}

\author{
Determinants of Tourism in the Bay of Camamu-BA for Tourism Planning and Local \\ Development
}

\section{Factores Determinantes de la Oferta Turística en la Bahía de Camamu-BA para la Planificación Del Turismo y Desarrollo Local}

Carlos Henrique leite Borges ${ }^{1}$

Sócrates Jacobo Moquete Guzmán ${ }^{2}$

Moema Maria Badaró Cartibani Midlej ${ }^{3}$

\section{Resumo}

Este trabalho objetivou avaliar a oferta turística a partir da percepção dos visitantes e da comunidade local, possibilitando assim estabelecer os principais fatores determinantes da oferta turística e em ultima análise a elaboração de um índice de adequação dos seus componentes ao desenvolvimento local. Utilizou-se a estatística multivariada, através da Análise Fatorial, como forma de determinar os fatores da oferta turística local e o seu índice. Os resultados revelaram um quadro onde os componentes da oferta turística local indicaram certa fragilidade, fato esse também refletido no índice proposto, e a necessidade de melhoria na qualidade de alguns fatores e intervenções urgentes em outros. Assim, visitantes e comunidade se aproximam em suas avaliações, com algumas especificidades em relação às características do lugar que precisam também ser contempladas no planejamento da atividade turística e do seu desenvolvimento.

Palavras-chave: Oferta turística; Avaliação; Fatores determinantes; Desenvolvimento local; Baía de Camamu.

\footnotetext{
${ }^{1}$ Economista, Mestre em Cultura e Turismo, professor do departamento de Economia, Universidade Estadual de Santa Cruz, Ilheus, BA. Brasil. chlborges@ hotmail.com

${ }^{2}$ Doutor em Ciência Política. Professor Adjunto da Universidade Estadual de Santa Cruz, Ilhéus, Bahia. Brasil. socrates_moquete@yahoo.com

${ }^{3}$ Economista. Doutora em Educação. Professora Titular da Universidade Estadual de Santa Cruz, Ilhéus, Bahia. Brasil.moema@uesc.br
} 


\begin{abstract}
This study aimed to assess the tourism from the perspective of the visitors and the local community, thus enabling to establish the main determinants of tourism and ultimately the development of an index of adequacy of its components to local development. It was used the multivariate analysis, through factor analysis as a way to determine the factors of the local tourist and its index. The results revealed a framework where components of the local tourist indicated a certain fragility, a fact also reflected in the proposed index, and the need to improve the quality of some factors and other urgent interventions. So, visitors and community approach in their assessments, with some specifics regarding the characteristics of place that must also be considered in the planning of tourism and its development
\end{abstract}

Keywords: Tourism's offer; Evaluation, Determinants; Local development; Bay of Camamu.

\title{
Resumen
}

Este trabajo tuvo como objetivo evaluar el oferta turística de la percepción de los visitantesy la comunidad local, lo que permitirá establecer los principales determinantes del turismo y en última instancia, el desarrollo de un índice de adecuación de sus componentes para el desarrollo local. Se utilizó un análisis multivariable, a través de análisis factorial como una forma de determinar los factores del ofeta turística local y su índice. Los resultados revelaron una foto donde los componentes del turismo local se indicafragilidad, un hecho también se refleja en el índice propuesto, y la necesidad de mejorar la calidad de algunos de los factores y otras intervenciones urgentes. De este modo, los visitantes y el enfoque de la comunidad en sus evaluaciones, con algunos detalles en relación con las características del lugar también debe abordarse en la planificación del turismo y su desarrollo.

Palabras-clave: Oferta turística; Evaluación; Factores determinantes; desarrollo local; Bahía de camamu.

\section{Introdução}

O turismo representa um conjunto de inter-relações em toda a cadeia produtiva, marcada essencialmente pela prestação de serviços resultando em grande mobilização de recursos humanos, físicos e financeiros. Representa também, e não em menor grau de importância, inter-relações sociais e culturais, promovendo não apenas geração de divisas cambiais, mas também possibilita que culturas transponham divisas territoriais.

A depender das condições em que acontece a atividade turística, do seu nível de desenvolvimento, da adequação dos seus componentes, tanto as trocas comerciais quanto as 
culturais podem gerar benefícios, mas também podem provocar tensões sociais e ambientais por conta das vicissitudes que a atividade oferece. È necessário um planejamento da atividade para que ao final, o destino esteja adequado ao bem estar dos visitantes e, sobretudo, às condições ambientais, sociais e culturais do lugar.

Precedendo ao planejamento, entende-se que uma avaliação do destino, materializada por meio dos seus componentes e de acordo com sua realidade, deve ser imprescindível para a conformação futura do local enquanto destino turístico que seja atraente para os visitantes e dimensionado para e com a comunidade anfitriã. Tal avaliação deve acontecer por parte de grupos interessados, como por exemplo, visitantes e moradores.

O estudo foi realizado na Baía de Camamu, um espaço territorial delimitado por uma identidade em comum que é o aspecto físico-territorial conferida pela Baía que une três municípios (Camamu, Igrapiúna e Maraú), sem contar com os aspectos da formação cultural e histórica que os envolvem. A Baía de Camamu representa não só um elo físico para essas localidades como também representa uma ligação de identidade cultural forjada através da história desde a fase de colonização brasileira quando serviu de palco para a exploração e comercialização de produtos da região, confrontos com indígenas, comércio de escravos, incursões jesuíticas, e servindo principalmente até hoje como fonte de renda para as comunidades ribeirinhas.

Atualmente este espaço, em especial o povoado de Barra Grande, no município de Maraú, revela-se como um dos principais destinos turísticos da alta estação no Litoral Sul da Bahia, com seu fluxo aumentando a cada ano e já sendo visível a necessidade premente de prepará-la para o turismo de forma competitiva e ao mesmo tempo adequada às características locais. A região possui enorme vocação para as atividades turísticas e de lazer por ser dotado de extenso litoral, com inúmeras praias e diversos atrativos naturais, culturais e históricos. No entanto, o crescimento do turismo já provoca alterações profundas no padrão de uso do solo e dos recursos naturais, bem como nas relações humanas locais onde esta atividade se desenvolve.

Ante o exposto, suscitam-se os seguintes questionamentos: Como os visitantes e residentes avaliam a oferta turística do destino Barra Grande, na Baía de Camamu? Os componentes da 
oferta turística na Baía de Camamu estão adequados aos anseios dos visitantes e dos residentes? Quais os principais fatores determinantes da oferta turística na Baía de Camamu? A oferta turística na Baía de Camamu está adequada ao Desenvolvimento Local?

Tais questionamentos foram respondidos através de uma análise a partir das percepções do visitante, pois ele, melhor do que ninguém poderá avaliar o que está posto à sua experiência e, também, do residente, representando um participante ativo na medida em que usufrui de tudo aquilo que o turismo oferece, sendo beneficiado e também sofrendo seus efeitos, importante também como avaliador.

O objetivo geral da pesquisa foi avaliar a oferta turística na Baía de Camamu a partir da percepção dos visitantes e residentes como forma de contribuir para o planejamento e adequação da atividade ao Desenvolvimento Local. Seus objetivos específicos foram: a) Caracterizar os componentes da oferta turística na Baía de Camamu a partir da avaliação dos visitantes e dos residentes; b) Estabelecer os principais determinantes e fatores da oferta turística; c) Elaborar o Índice da Oferta Turística Local para avaliar sua adequação ao Desenvolvimento Local.

Considerando as variáveis e a interdependência entre elas, tal análise foi realizada através da estatística, descritiva e multivariada, onde se utilizou a análise fatorial como método de correlacionar as variáveis envolvidas no estudo, e com isso apresentar os determinantes da oferta turística na Baía de Camamu.

\section{A Oferta Turística: Componentes, Planejamento e Adequação ao Desenvolvimento}

\section{Local}

A oferta turística representa a materialização das condições físicas, humanas, culturais, socioeconômicas, políticas, culturais e naturais que um destino possibilita para a experiência do visitante. $\mathrm{O}$ estágio de desenvolvimento e qualidade da sua estrutura é essencial para a atividade turística e não menos também para a comunidade receptora, pois, compreende o conjunto de instalações, equipamentos, serviços e espaços compartilhados por visitantes e residentes, logo, de difícil demarcação sobre o que é ou não é turístico. 
Os componentes da oferta turística, sejam naturais ou culturais, estão presentes em quase todas as sociedades podendo alguns se constituírem como forte valor de atração pelas suas características únicas ou diferenciadoras.

Ignarra (2003) classifica os componentes da oferta turística em cinco categorias principais: Atrativos naturais (São compostos pelo ar, clima, acidentes geográficos, o terreno, a flora, a fauna, as massas de água, as praias, as belezas naturais, o abastecimento de água potável e outros); Atrativos culturais (São compostos pelo patrimônio arquitetônico, pelos acervos dos museus, pela cultura da população, sua gastronomia típica, seu artesanato, folclore, seus eventos, hábitos e costumes, sua música, literatura, língua etc.); Serviços turísticos (São compostos pelos serviços que têm na demanda turística a maior parte de suas receitas, tais como: meios de hospedagem, transportes turísticos, locação de veículos e embarcações, serviços de alimentos e bebidas, serviços de organização de eventos, espaços de eventos, serviços de entretenimento, serviços de receptivo turístico etc.); infraestrutura (Composta pelo conjunto de construções subterrâneas e de superfície, como os sistemas de abastecimento de água e de coleta, tratamento e despejo de esgotos, redes de distribuição de gás, coleta de águas pluviais, telefonia, distribuição de energia elétrica e de iluminação pública, sistema viário, mobiliário urbano e terminais de transportes); Serviços urbanos de apoio ao turismo (São compostos pelos serviços bancários, de saúde, de comunicações, de segurança pública, de apoio a automobilistas, além de comércio especializado para turistas).

Assim, a oferta turística é esse composto de elementos que define o destino turístico e também pode determinar o tipo de desenvolvimento que se espera para a localidade. Defendese neste trabalho um modelo de desenvolvimento do turismo com inserção e participação da comunidade receptora e com a adequação da oferta turística ao bem estar do visitante, mas, sobretudo às condições físico-ecológicas do ambiente natural e às características da cultura local.

Uma adequação satisfatória da oferta turística às necessidades de uma demanda cada vez mais crescente e criteriosa passa por uma avaliação da qualidade e da disponibilidade de bens e serviços que atendam ao bem-estar daqueles que os usufruem. Tal avaliação pode significar importante instrumento para a qualificação da oferta turística de um lugar e a partir de então o estabelecimento de bases que subsidiem o planejamento e a gestão do destino. 
Moniz (2006), em seu estudo, afirma que o centro das atenções do planejamento turístico variou ao longo do tempo: de uma focalização exclusiva no planejamento físico de instalações turísticas e sua posterior promoção, passou-se para uma abordagem mais ampla, que toma em consideração as necessidades tanto das empresas, como dos próprios turistas e da comunidade receptora, havendo cada vez mais uma maior preocupação em criar sinergias entre o turismo e o ambiente social, econômico e natural.

Entende-se que para além da satisfação do turista, a atividade deve ser adequada também para o bem-estar daqueles que por muitas vezes dependem exclusivamente da dinâmica econômica do turismo e que usufruem dos equipamentos e serviços comuns aos visitantes. Nesta perspectiva os moradores desempenham papel essencial quando da avaliação dos componentes turísticos.

\section{Perspectivas, Impactos e Contribuições do Turismo para Desenvolvimento Local}

É fato que a atividade turística traz benefícios, mas também oferece impactos negativos apresentando características de um modelo econômico desintegrador. Segundo Grünewald (2003) o desenvolvimento turístico poderia levar os nativos de pequenas sociedades hospedeiras a abandonarem um modo de vida tradicional para se inserirem em negócios locais incrementados pelo efeito multiplicador do desenvolvimento turístico. Tal contexto é responsável por fenômenos significativos de exclusão social, descaracterização cultural e degradação ambiental (MENDONÇA; IRVING, 2006).

Esse quadro, resultado de condições impostas por um modelo de desenvolvimento imediatista, começa a apresentar possibilidades outras, mais positivas. Segundo Coriolano (2003), "São experiências novas que surgem ligadas ao campo e às cidades, inclusive práticas de desenvolvimento local incentivadas pelo turismo".

Tal modelo de desenvolvimento está pautado na cooperação entre os agentes econômicos com interesses em comum para certa localidade através das potencialidades internas, fortalecimento das relações sociais entre os diversos agentes, inclusive o governo local, e participação comunitária nas decisões estratégicas, visando um processo que resulte no 
desenvolvimento local. Não se trata de uma redução de escala do desenvolvimento, mas, uma proposta de um novo modelo de desenvolvimento.

O termo "local" não representa um simples reducionismo espacial. Paula (2001) descreve-o como qualquer recorte socioterritorial delimitado a partir de uma característica eletiva definidora de identidade. Pode ser uma característica físico-territorial (localidades de uma mesma microbacia), uma característica econômica (localidades integradas por uma determinada cadeia produtiva), uma característica étnico-cultural (localidades indígenas, remanescentes de quilombos), uma característica político-territorial (municípios de uma microrregião).

Para Franco (2001), outra referencia do "local" no termo desenvolvimento local é a idéia de comunidade. Explica o autor:

O desenvolvimento local, de certo modo, troca a generalidade abstrata de uma sociedade global configurada à semelhança ou como suporte do Estado (como é o caso das sociedades de massa) pelas particularidades concretas das múltiplas minorias sociais orgânicas que podem projetar...(endogenamente) futuros alternativos para a coletividade e, sobretudo, antecipar esses futuros em experiências presentes (FRANCO, 2001, P.28).

Para Trevizan (2006) "o local", a "comunidade que envolve o local" e a "participação da comunidade" nos processos que resultam em condições favoráveis ao turismo "sustentável", a partir do patrimônio natural e/ou cultural têm como variável interveniente a construção de uma identidade da comunidade consigo mesma e com o local.

A identidade da comunidade consigo mesma acontece quando os seus integrantes se reconhecem como pertencentes a ela em função de um conjunto de afinidades comuns. A identidade da comunidade com o local ocorre quando um conjunto de características físicas e culturais pertencentes ao espaço em que se situa a comunidade é reconhecido por seus membros, individual ou coletivamente, como a eles pertencentes e, por isto, como sendo de sua responsabilidade zelar por elas. A sensação de pertencimento leva à participação espontânea, ou à reivindicação por ela quando pessoas ou grupos se sentirem isolados dos processos que levam à tomada de decisões no âmbito comunitário, especialmente quando os significados coletivos não forem respeitados (TREVIZAN, 2006, p.15). 
O Desenvolvimento Local a partir do turismo, então, deverá assentar-se em uma atividade economicamente viável e de qualidade nos seus serviços de apoio ao visitante, na sua infraestrutura e nos seus serviços essencialmente turísticos, capaz de promover ocupação para a mão de obra local com geração de renda principal e/ou complementar, uma atividade turística baseada na participação da comunidade, na cooperação e fortalecimento das redes associativas locais, e estas com seu entorno, com a capacidade de dinamizar, usufruir e valorizar suas potencialidades endógenas, ou seja, seu "patrimônio", aquilo que pertence unicamente àquele lugar, seja natural e/ou cultural.

O desenvolvimento de um destino turístico em bases "locais" deverá estar configurado nestes atributos, deverá apresentar componentes da oferta turística adequada a estes propósitos, sustentada nestes critérios, uma Oferta Turística Local. Neste sentido, como ponto inicial para se chegar a esta Oferta Turística Local, é imprescindível o planejamento para sua configuração, e este, necessita sem dúvida, de uma avaliação que inclua a percepção também do residente, ou seja, sua participação e envolvimento devem começar pela sua avaliação dos componentes turísticos do local.

\section{Procedimentos Metodológicos}

\section{1. Área de estudo}

A Baía de Camamu, terceira maior do Brasil, está localizada na região econômica denominada Litoral Sul, Território de Identidade Baixo sul e dentro da Zona Turística Costa do Dendê. Delimita um espaço geográfico formado em seu entorno por três municípios, entre eles, aquele que empresta seu nome à Baía. Envolve os municípios de Camamu, Maraú e Igrapiúna. A população vive basicamente de uma economia agrícola baseada no cultivo de culturas nativas, do comércio e, nas regiões litorâneas, da pesca e do turismo. Aliada ao patrimônio natural dispõe, ainda, de inestimável riqueza arquitetônica e cultural: casarões, igrejas, conventos, casas de fazendas, além de algumas manifestações populares que compõe seu valiosíssimo acervo cultural. 
A pesquisa ocorreu especificamente no povoado de Barra Grande nos limites do município de Maraú. Barra Grande, antiga vila de pescadores, é hoje o principal destino turístico da península de Maraú, atraindo visitantes de todas as partes do país e até de outros países que aproveitam os feriados ou o período de alta estação para desfrutar dos seus atrativos naturais. Segundo Maia (2008) o povoado e seu entorno concentra uma população de cerca de 1.700 habitantes, chegando a alcançar um número cinco vezes maior na alta estação. A localidade concentra a maioria dos hotéis e pousadas e melhor infraestrutura em toda a Península.

\subsection{Fonte e coleta de dados}

Os dados primários foram obtidos através de aplicação de questionários a uma amostra de 103 moradores e 97 visitantes determinada por meio não-probabilístico através da técnica da exaustão no período de 30 de dezembro de 2009 a 02 de janeiro de 2010. Os visitantes foram abordados nas ruas, praias e cabanas. Os moradores pesquisados foram aqueles envolvidos com a atividade turística mais diretamente como: barqueiros, comerciantes, proprietários de barracas de praias, funcionários de estabelecimentos comerciais, funcionários de restaurantes e de barracas de praia e artesãos.

Os indicadores utilizados foram selecionados tendo por base trabalhos realizados na mesma temática como os de Cerqueira (2002) e Cerqueira e Freire (2008), adaptados ao local de estudo, conforme Quadro 1.

Quadro 1: Relação de indicadores representativos da oferta turística na comunidade de Barra Grande, Baía de Camamu.

\begin{tabular}{|l|l|l|}
\hline \multicolumn{2}{|c|}{ Indicador } & \multicolumn{1}{c|}{ Dimensão da avaliação } \\
\hline X1 & Atrativos naturais & $\begin{array}{l}\text { Beleza da paisagem, das praias, rios, elementos } \\
\text { geográficos etc.. }\end{array}$ \\
\hline X2 & Patrimônio arquitetônico & $\begin{array}{l}\text { Percepção dos elementos culturais construídos presentes } \\
\text { no local de estudo }\end{array}$ \\
\hline X3 & Artesanato local & Qualidade e diversidade das peças artesanais do local \\
\hline X4 & Manifestações populares & $\begin{array}{l}\text { Percepção da presença e diversidade das manifestações } \\
\text { populares tradicionais }\end{array}$ \\
\hline
\end{tabular}




\begin{tabular}{|c|c|c|}
\hline $\mathrm{X} 5$ & Gastronomia local & $\begin{array}{l}\text { Qualidade, originalidade e diversidade da gastronomia } \\
\text { local }\end{array}$ \\
\hline $\mathrm{X} 6$ & Equipamentos de lazer & $\begin{array}{l}\text { Qualidade e disponibilidade de equipamentos para o lazer } \\
\text { e entretenimento no destino turístico }\end{array}$ \\
\hline $\mathrm{X} 7$ & Passeios oferecidos & $\begin{array}{l}\text { Qualidade, diversidade e programação dos passeios } \\
\text { planejados para o local }\end{array}$ \\
\hline $\mathrm{X} 8$ & Informações turísticas prestadas & $\begin{array}{l}\text { Qualidade e precisão das informações prestadas sobre o } \\
\text { local }\end{array}$ \\
\hline $\mathrm{X} 9$ & Guias de turismo & $\begin{array}{l}\text { Capacidade e habilidade de orientar e informar os } \\
\text { visitantes sobre os atrativos e informações úteis do local. }\end{array}$ \\
\hline $\mathrm{X} 10$ & Hospitalidade & $\begin{array}{l}\text { Forma como a comunidade recebe e trata os visitantes } \\
\text { durante o período de visitação }\end{array}$ \\
\hline $\mathrm{X} 11$ & Meios de hospedagem & $\begin{array}{l}\text { Disponibilidade e qualidade dos leitos e acomodações das } \\
\text { pousadas e hotéis do local }\end{array}$ \\
\hline $\mathrm{X} 12$ & Diversões noturnas & $\begin{array}{l}\text { Disponibilidade, diversidade e qualidade das diversões } \\
\text { noturnas no local }\end{array}$ \\
\hline $\mathrm{X} 13$ & Serviço de receptivo turístico & $\begin{array}{l}\text { Capacidade e qualidade no atendimento e recepção e } \\
\text { translado do visitante }\end{array}$ \\
\hline $\mathrm{X} 14$ & Sinalização turística & $\begin{array}{l}\text { Disponibilidade e qualidade da sinalização turística } \\
\text { horizontal e vertical }\end{array}$ \\
\hline $\mathrm{X} 15$ & Serviços de alimentação & $\begin{array}{l}\text { Disponibilidade, quantidade e qualidade dos } \\
\text { estabelecimentos com serviços de alimentação } \\
\text { (restaurantes, bares, lanchonetes, cabanas) }\end{array}$ \\
\hline $\mathrm{X} 16$ & Abastecimento de água & Disponibilidade e qualidade do fornecimento de água \\
\hline $\mathrm{X} 17$ & Pavimentação das ruas & Condições da pavimentação das ruas \\
\hline $\mathrm{X} 18$ & Sinalização urbana & Quantidade e qualidade das placas de sinalização urbana \\
\hline $\mathrm{X} 19$ & Limpeza pública & $\begin{array}{l}\text { Condições de higiene e qualidade da limpeza das ruas, } \\
\text { avenidas e praças }\end{array}$ \\
\hline $\mathrm{X} 20$ & Serviços de comunicação & $\begin{array}{l}\text { Qualidade e facilidade de acesso aos meios de } \\
\text { comunicação (telefones púbicos, sinal de celular etc) }\end{array}$ \\
\hline $\mathrm{X} 21$ & Transporte intermunicipal & $\begin{array}{l}\text { Disponibilidade do transporte intermunicipal para acesso e } \\
\text { saída do local }\end{array}$ \\
\hline
\end{tabular}




\begin{tabular}{|c|c|c|}
\hline $\mathrm{X} 22$ & Transporte marítimo & Disponibilidade, qualidade e condições das embarcações \\
\hline $\mathrm{X} 23$ & Terminal marítimo & $\begin{array}{l}\text { Qualidade da estrutura física e de acomodação dos } \\
\text { terminais marítimos }\end{array}$ \\
\hline $\mathrm{X} 24$ & Terminal urbano & $\begin{array}{l}\text { Qualidade da estrutura física e de acomodação do terminal } \\
\text { urbano }\end{array}$ \\
\hline $\mathrm{X} 25$ & Serviços bancários & $\begin{array}{l}\text { Facilidade de acesso e disponibilidades de rede bancária } \\
\text { no local }\end{array}$ \\
\hline $\mathrm{X} 26$ & Aceitação de cartão de crédito & $\begin{array}{l}\text { Facilidade de aceitação de pagamentos por cartão de } \\
\text { crédito }\end{array}$ \\
\hline $\mathrm{X} 27$ & $\begin{array}{l}\text { Valor das diárias nos meios de } \\
\text { hospedagem }\end{array}$ & $\begin{array}{l}\text { Preço e condições de pagamento das diárias em hotéis e } \\
\text { pousadas }\end{array}$ \\
\hline $\mathrm{X} 28$ & Valor dos serviços de alimentação & $\begin{array}{l}\text { Preço e condições de pagamento da alimentação nos } \\
\text { restaurantes, bares, lanchonetes e cabanas de praia }\end{array}$ \\
\hline $\mathrm{X} 29$ & Valor dos serviços de entretenimento & Preço dos entretenimentos locais \\
\hline $\mathrm{X} 30$ & Coleta de lixo & $\begin{array}{l}\text { Condições do serviço de coleta de lixo nas ruas, praias, } \\
\text { rios, mangues }\end{array}$ \\
\hline $\mathrm{X} 31$ & $\begin{array}{l}\text { Limpeza dos banheiros das cabanas de } \\
\text { praias, bares e restaurantes }\end{array}$ & $\begin{array}{l}\text { Condições de higiene e qualidade ambiental dos banheiros } \\
\text { das cabanas, bares e restaurantes }\end{array}$ \\
\hline $\mathrm{X} 32$ & $\begin{array}{l}\text { Distribuição da rede de esgoto nas ruas, } \\
\text { praias, rios }\end{array}$ & Condições do serviço de saneamento básico \\
\hline $\mathrm{X} 33$ & Limpeza das embarcações & $\begin{array}{l}\text { Limpeza e higiene dos barcos e lanchas à disposição dos } \\
\text { usuários }\end{array}$ \\
\hline
\end{tabular}

A avaliação foi realizada pela atribuição de notas aos indicadores de acordo com uma escala tipo Likert que variava de zero (0) a cinco (5) baseada nas seguintes escolhas: (0) quando o informante não sabe ou não conhece nada do componente; (1) se considerar o indicador como péssimo; (2) se considerar ruim; (3) para uma avaliação do tipo regular; (4) considerando bom e (5) se o componente da oferta turística for avaliado como ótimo. Este tipo de escala foi criado em 1932 por Rensis Likert e desde então é largamente utilizado em processos de avaliação onde o entrevistado assinala um único item de acordo com seu grau de satisfação, comumente encontrada em questionários de pesquisa de mercado, pois ela é de simples 
construção e dá liberdade para que os seus respondentes coloquem ali seu verdadeiro sentimento (MALHOTRA, 2001).

\subsection{Tratamento e análise dos dados}

Os dados foram tratados e analisados utilizando-se o método estatístico. Através da estatística descritiva foram trabalhadas as informações acerca dos turistas e moradores e suas notas atribuídas ao conjunto de indicadores avaliados. Também foi utilizada a estatística multivariada através da Análise Fatorial.

A Análise Fatorial é uma técnica estatística multivariada que pode sintetizar as informações de um grande número de variáveis em um número muito menor chamados de fatores (HAIR, 2003). De acordo com Maroco (2003) esses fatores permitem identificar as relações estruturais entre as variáveis que de outra forma passariam despercebidas no conjunto vasto de variáveis originais. Esses fatores foram extraídos através do método da Análise dos Componentes Principais (ACP). Logo em seguida, a partir dos fatores, foi elaborado o índice da oferta turística local

\subsection{Elaboração do índice da oferta turística local}

Após a seleção dos Fatores determinantes da oferta turística foi pensado a criação de um índice que resumisse tais informações e apresentasse as condições da oferta turística em termos de um parâmetro baseado na percepção dos visitantes e dos moradores. O índice, adaptado de Lopes et al (2009), foi obtido pelo somatório do produto entre o escore (nota

média geral) de cada variável/indicador $(\bar{I})$ e o termo de ponderação dos indicadores no índice (p). O valor encontrado é apresentado em termos do escore máximo possível (k), ou seja a nota " 5 ", multiplicando-o pelo fator $1 / \mathrm{k}$, permitindo assim estabelecer o índice em uma escala de " $0,00 "$ a " $1,00 "$ ". A nota média geral dos indicadores foi obtida somando-se as notas médias dos visitantes e dos moradores para cada indicador selecionado e dividido por dois. A expressão algébrica do índice é dada pela Equação 01:

$$
i=\left(I_{1} \cdot p_{1}+\bar{I}_{2} \cdot p_{2}+\bar{I}_{i} \cdot p_{i}\right) \cdot \frac{1}{k}
$$


Onde,

$\mathrm{i}$ = índice de adequação da oferta turística local

$\bar{l}=\frac{\mathrm{Iv}+\mathrm{Ir}}{2}$

Iv = nota média dos indicadores atribuída pelos visitantes;

Ir = nota média dos indicadores atribuída pelos residentes;

$\mathrm{k}=$ nota máxima possível $(=5)$ (permite estabelecer o índice em uma escala de 0 a 1);

$\mathrm{p}=$ termo de ponderação dos indicadores (peso associado a cada fator).

O valor do peso (pi) atribuído a variável foi determinado em função do autovalor da componente (raiz característica) associado à explicabilidade de cada variável, em relação às componentes principais extraídas (equação 02). O autovalor é utilizado como termo de ponderação por expressar a capacidade dos fatores em captar em níveis diferentes as variâncias das variáveis (PALÁCIO, 2004) citado por Lopes (2009). O peso de cada variável/indicador foi obtido a partir da Equação 02 abaixo:

$\mathrm{p}_{\mathrm{i}}=\frac{\left(\mathrm{F}_{1} \cdot \mathrm{C}_{1}\right)+\left(\mathrm{F}_{2}, \mathrm{C}_{2}\right) \ldots+\left(\mathrm{F}_{1} \cdot \mathrm{C}_{1}\right)}{\left(\mathrm{F}_{1} \cdot \sum_{1}^{\mathrm{n}} \mathrm{C}_{1}\right)+\left(\mathrm{F}_{2} \cdot \sum_{1}^{\mathrm{n}} \mathrm{C}_{2}\right) \ldots+\left(\mathrm{F}_{1} \cdot \sum_{1}^{\mathrm{n}} \mathrm{C}_{1}\right)}$

Onde,

pi $=$ peso associado a cada indicador ;

$\mathrm{Fi}$ = Autovalor de cada fator;

$\mathrm{Ci}$ = explicabilidade da variável em relação ao fator 


\section{Resultados e discussões}

\subsection{Adequação dos dados à analise fatorial}

Como forma de verificar a conformidade dos dados aplicados a analise fatorial foi realizado alguns testes estatísticos à amostra antes de proceder a extração dos fatores. Inicialmente procurou-se identificar a consistência interna dos indicadores através do Coeficiente Alpha de Cronbach. Assim, constatou-se que o coeficiente em questão ficou dimensionado em 0,904, aceitável então em relação à consistência dos dados.

Em seguida verificaram-se as comunalidades para os indicadores, sendo que todos eles apresentaram valores acima de 0,50, o que os tornam viáveis para a Análise Fatorial. As comunalidades são quantidades das variâncias (correlações) de cada variável explicada pelos Fatores. Quanto maior a comunalidade, maior será o poder de explicação daquela variável pelo Fator.

Posteriormente realizou-se o teste de esfericidade de Bartlett, atingindo um valor igual a 1573,19 , com significância a $0,00 \%$ de probabilidade, permitindo rejeitar a hipótese nula de que a matriz de correlação é uma matriz identidade, ou seja, de que as variáveis não são correlacionadas. Conjuntamente como forma de avaliar a adequação da análise fatorial ao conjunto de dados, verificou-se a medida de adequação da amostra (KMO), com valor igual 0,811 .

O indicador "X1 - Atrativos naturais" por apresentar uma freqüência do conceito ótimo maior que $90 \%$ tanto para os visitantes quanto para os residentes, foi retirado da análise em virtude de representar pouca importância em termos de variabilidade estatística. Essa quase unanimidade na avaliação do componente o coloca em patamar diferenciado em relação às outras variáveis em termos de variância estatística e pode ser considerado como o principal componente de atração turística do local.

\subsection{Componentes principais e Fatores determinantes da oferta turística local}

A análise fatorial resultou em uma matriz de correlação com dez fatores com autovalores acima de 1,00 e respondendo por $67,88 \%$ da variância total dos dados utilizados. 
Foram considerados como Fatores determinantes da oferta turística na Baía de Camamu, em especial no povoado de Barra Grande, aqueles indicadores que apresentaram cargas fatoriais acima de 0,60, o que representa uma forte associação entre a variável e o Fator. A Tabela 1, a seguir, destaca as cargas fatoriais e apresenta os Fatores extraídos e nomeados com seus respectivos indicadores.

Tabela 1: Fatores determinantes da Oferta Turística Local na Baía de Camamu

\begin{tabular}{l|l}
\hline Fator & Carga fatorial \\
\hline F1 - Experiência no translado marítimo pela Baía de Camamu & \\
Transporte marítimo & 0,864 \\
Terminal marítimo & 0,703 \\
Limpeza e higiene das embarcações & 0,749 \\
\hline
\end{tabular}

F2 - Capacidade de recepcionar e de prestar informações aos visitantes

Informação turística $\quad 0,752$

$\begin{array}{ll}\text { Guia turístico } & 0,670\end{array}$

Receptivo turístico $\quad 0,625$

F3 - Custo com serviços de acomodação e alimentação

Valor da diária em hotéis e pousadas $\quad 0,679$

$\begin{array}{ll}\text { Valor da alimentação em restaurantes } & 0,790\end{array}$

F4 -Bem estar na locomoção e acesso aos meios d hospedagem

$\begin{array}{ll}\text { Meios de hospedagem } & 0,632\end{array}$

$\begin{array}{ll}\text { Pavimentação } & 0,726\end{array}$

Sinalização urbana $\quad 0,602$

F5 - Condições sanitárias e ambientais do local

$\begin{array}{ll}\text { Coleta de lixo nas ruas e praias } & 0,730\end{array}$

$\begin{array}{ll}\text { Limpeza e higiene dos banheiros das barracas de praias } & 0,697\end{array}$

Distribuição do esgoto nas praias, rios, lagos, ruas $\quad 0,625$

F6 - Patrimônio material da cultura local

Patrimônio arquitetônico $\quad 0,762$

$\begin{array}{lr}\text { Artesanato local } & 0,611\end{array}$ 
F7 - Oferta de entretenimentos noturnos

Diversão noturna

0,723

F8 - Patrimônio imaterial da cultura local

Manifestações populares

0,666

Gastronomia local

0,694

F9 - Qualidade e diversidade dos passeios oferecidos

Passeios oferecidos

0,626

F10 - Capacidade de abastecimento de água

Abastecimento de água

0,825

Fonte: dados da pesquisa

O primeiro Fator é composto por 03 variáveis que respondem por 25,95\% da variabilidade das informações e estão representadas pelos indicadores X22-Transporte marítimo; X23 Terminal marítimo e X33- Limpeza dos barcos. Esse fator, de acordo com as correlações expressas, indica uma preocupação e importância atribuída pelos visitantes e moradores quanto às condições do deslocamento dos usuários pela Baía de Camamu. Tais condições refletem os aspectos de segurança, qualidade do transporte e higiene, ou seja, representa o bem estar e qualidade da experiência do deslocamento marítimo. Parece significativo ter esse fator como o de maior explicabilidade pelo fato de ser esse ainda o principal meio de acesso dos visitantes à localidade e ser o principal elo entre os moradores de Barra Grande e o acesso aos serviços e bens que o local não comporta.

Para o visitante representa o primeiro contato com a exuberância da paisagem do lugar, um momento de contemplação com todo o ambiente à sua volta. De fato, a viajem, seja de barco ou de lancha, da costa (Camamu) rumo á Barra Grande foi muitas vezes relatadas pelos visitantes como um momento "único". A importância desse Fator chama a atenção para o cuidado que se deve ter com a estrutura e condições que permitem o deslocamento dos moradores e principalmente dos turistas pela baía, desde o embarque até o desembarque, representado pela variável "terminal marítimo", passando pelas condições de transportes e higiene dos barcos e lanchas. Recorrendo aos dados da análise descritiva percebe-se que os indicadores obtiveram notas médias de 3,95; 3,06 e 3,58 respectivamente pelos residentes, e 
médias de 3,21; 2,83 e 2,86 pelos visitantes. Dessa forma tal fator foi nomeado como "Experiência no translado marítimo pela Baía de Camamu".

O segundo Fator responde por 7,63\% da variância dos dados e está fortemente correlacionado com as variáveis X8 - Informações turísticas; X9 - Guias turísticos e X13 - Receptivo turístico. Esse fator indica a qualidade do acolhimento e das informações prestadas aos visitantes sob a ótica do próprio visitante e do morador. Qualquer destino turístico deve conceber a recepção do visitante como prioridade, pois representa para aquele um serviço de balcão onde os serviços e atrativos do lugar estarão dispostos através de um cardápio de possibilidades o que faz com que as pessoas e profissionais à frente dessa receptividade, ou melhor, atrás desse balcão, sejam responsáveis em grande parte pela qualidade da visita no local. Assim esse fator foi nomeado como "Capacidade de recepcionar, orientar e prestar informações aos visitantes.

O terceiro Fator foi categorizado como "Custo com os serviços de estadia e alimentação" e responde por 6,48\% da variância dos dados. Compõe esse fator as variáveis X27 - Valor das diárias nos meios de hospedagem e X28 - Preço da alimentação. Esse fator indica a percepção do turista e do morador quanto ao custo dos serviços básicos de alimentação e estadia na localidade. Para os visitantes representa um importante fator na tomada de decisão para a viagem e, de acordo com a análise descritiva, revelou sinalizando uma estrutura de preços não compatível com as expectativas dos visitantes. Cerca de $44 \%$ dos visitantes avaliaram o preço da diária nos meios de hospedagem como "ruim" ou "péssimo", e 34\% fizeram a mesma avaliação para os preços de alimentação, com notas médias de 2,17 e 2,67 respectivamente.

O Fator seguinte apresentou capacidade de explicabilidade de 5,28\% da variância e foi representado pelas variáveis X11 - Meios de hospedagem; X17 - Pavimentação e X18 Sinalização urbana. Esse fator sugere o bem estar na locomoção do visitante pela localidade e principalmente as condições de acesso aos hotéis e pousadas. A comunidade Barra Grande caracteriza-se como uma pequena vila onde apresenta ruas sem pavimentação e talvez por esse motivo tenha recebido uma nota média dos turistas de 2,49. No entanto, alguns moradores e também alguns visitantes durante a pesquisa relataram não enxergar isso como um problema, e sim, uma característica local que deve ser preservada, sendo eles contrários a pavimentação das suas ruas. Voltando às estatísticas descritivas, constata-se que a avaliação 
do tipo "ótimo" ou "bom" para o indicador Pavimentação foi indicada por 33,30\% dos moradores e por $26,19 \%$ dos visitantes.

O quinto Fator está associado com o aspecto ambiental sendo nomeado como "Condições sanitárias e ambientais" e sendo representado pelas variáveis X30 - Coleta de lixo; X31 Limpeza dos banheiros das barracas de praia e X32 - Distribuição da rede de esgoto, e responde por $4,77 \%$ da variabilidade dos dados. As condições sanitárias sempre vão exercer forte impacto em um destino turístico e em Barra Grande não foi diferente. Esse constructo fatorial é determinante tanto para os visitantes quanto para os moradores. Para os visitantes os aspectos contidos neste fator podem definir a qualidade da visitação e da experiência vivenciada na localidade e, para os moradores, representam as condições que definem a sua qualidade de vida.

De acordo com a análise descritiva, estes componentes apresentaram notas médias muito baixas pelos dois grupos de entrevistados, o que revela ser um fator que apresenta indicadores em condições não satisfatórias em termos sanitários e ambientais. Para 71,84\% dos moradores o indicador correspondente ao esgotamento sanitário foi avaliado como "ruim" ou "péssimo" com nota média de 1,31 e para os visitantes esta mesma avaliação atingiu 22,62\% das respostas, com nota média de 1,87, uma proporção menor em virtude de um menor alcance na avaliação deste indicador em comparação aos moradores que vivenciam essas condições cotidianamente.

O sexto Fator nomeado como "Patrimônio material da cultura local" foi responsável por 4,08\% da variância e está representado pelas variáveis X2 - Patrimônio arquitetônico e X3 Artesanato local. Esse fator que está relacionado com o conjunto dos atrativos culturais do lugar e as variáveis que o compõem representam o contato do visitante e a percepção dos moradores com uma parte da cultura material da Baía de Camamu. O Patrimônio arquitetônico foi avaliado como "ótimo " ou "bom" por cerca de $40 \%$ dos residentes e por $50 \%$ dos visitantes. O Artesanato local também obteve uma avaliação relativamente boa com $51 \%$ das respostas dos visitantes e $57 \%$ dos moradores considerando este indicador como "ótimo" ou "bom". 
É sabido que o principal motivo de atratividade desse lugar é a beleza natural, constituindo-se como um destino de turismo de sol e mar. Esse fator apresenta indicadores que chama a atenção para o fato de se trabalhar e potencializar o patrimônio cultural material apresentando-o como um componente da oferta turística complementar.

O sétimo Fator apresenta apenas uma variável com forte correlação a ele associada, a variável X12 - Diversão noturna. Esse indicador foi melhor avaliado pelos visitantes do que pelos moradores. Por parte dos moradores a avaliação reflete algum nível de insatisfação pois $62 \%$ das respostas consideraram "regular", "ruim" ou "péssimo". Quanto aos visitantes essa proporção foi bem menor sendo que para $50 \%$ deles o indicador foi avaliado como "ótimo" ou "bom". Tal fato pode ser compreendido em virtude de no período de maior fluxo turístico, no verão, acontecer uma movimentação maior em termos de festas e eventos noturnos, o que explicaria uma melhor avaliação por parte dos turistas enquanto que o alcance dessa avaliação por parte dos moradores é muito maior constatando que esse tipo de lazer é escasso para este grupo nos outros meses do ano.

O Fator 8 traz dois indicadores de maior peso que são o indicador X4 - Manifestações populares e X5 - Gastronomia local. Esse fator foi nomeado como "Patrimônio imaterial da cultura local" e representa o conjunto de saberes acumulados pelas gerações e no caso específico do local estudado está manifestado pelo saber culinário e pela cultura local representada pelas manifestações tradicionais. A gastronomia local obteve a terceira melhor nota média dentre os indicadores avaliados pelos visitantes com um valor de 3,86 e com 69\% das respostas considerando este indicador como "ótimo" ou "bom" e sem nenhuma avaliação do tipo "ruim" ou "péssimo".

O indicador também foi bem avaliado pelos moradores com nota média de 3,81. A avaliação da gastronomia local para os dois grupos se aproximou do conceito "bom" o que indica que este traço local tem qualidade aceitável e um potencial que pode ser melhor explorado e trabalhado para aumentar ainda mais o seu nível de aceitação.

Quanto às manifestações populares, sua avaliação pelos visitantes não foi tão satisfatória como o componente anterior, apresentando uma nota média de 1,92 pontos. Pouco mais de $16 \%$ dos visitantes consideraram como boa e quase $23 \%$ avaliaram como regular. No entanto, 
a maior parcela dos entrevistados $(41,67 \%)$ responderam desconhecer sobre algum tipo de manifestação popular. Esse dado mostra que uma parcela expressiva dos entrevistados não tiveram acesso ou não perceberam alguma manifestação da cultura local e daqueles que perceberam apenas 7,14\% consideraram como ótima. Cabe ressaltar que a avaliação desse item entre péssimo e ótimo não diz respeito á qualidade das manifestações e sim da percepção do visitante sobre a existência de manifestações da cultura local.

O Fator 9 apresentou apenas um indicador relevante e fortemente associado aos passeios oferecidos. Este indicador tem sua importância para a oferta turística local, pois está intimamente ligado ao seu principal componente que é a paisagem e conjunto de belezas naturais. Um passeio de qualidade e bem programado pode enriquecer ainda mais a experiência do turista pois o coloca em contato mais estreito com os atrativos naturais do destino. Em Barra Grande este componente foi bem avaliado pelos dois grupos entrevistados. $59 \%$ dos visitantes e $56 \%$ dos moradores sinalizaram como "ótimo" ou "bom" o serviço de passeios oferecidos na localidade.

O Fator 10 foi o que apresentou menor variabilidade dos dados, mas não menos importante ele é, pois é constituído pela variável X16 - Abastecimento de água, sendo determinante para a visitação e também é sensivelmente afetado por ela, pois, com o aumento do fluxo turístico a demanda sobre o serviço de abastecimento aumenta consideravelmente na alta estação e sem uma adequada infraestrutura a localidade pode apresentar uma insuficiência no atendimento comprometendo a satisfação dos visitantes e da comunidade receptora. No povoado de Barra grande não existe rede pública de abastecimento de água, toda água utilizada para consumo doméstico é proveniente de poços artesianos individuais o que torna o destino mais vulnerável em relação a quantidade e qualidade da água disponível diante do aumento da população na alta estação.

A avaliação das condições da oferta turística da Baía de Camamu a partir da percepção das visitantes e dos moradores em forma de notas submetidas à análise fatorial permitiu determinar os principais fatores com seus indicadores de maior representatividade. Como forma de sintetizar tais informações e apresentar um quadro do estado atual da oferta turística, este trabalho também se propôs a elaborar um índice com base nos indicadores selecionados 
pela analise fatorial. A próxima seção apresentará os cálculos, composição e o resultado para o índice proposto.

\section{3. Índice da oferta turística local}

A partir da Equação 02 foi possível encontrar os pesos de todos os indicadores avaliados. Para a construção do índice levou-se em conta apenas as variáveis com maior poder de explicação, aquelas selecionadas através dos fatores juntamente com seus pesos. Essas variáveis representaram $65 \%$ do peso total do conjunto de variáveis e assim os pesos individuais dos indicadores foram calculados em função do peso do conjunto das variáveis selecionadas em relação ao conjunto total dos dados.

Tabela 2: Componentes principais da oferta turística com seus pesos.

\begin{tabular}{|c|c|c|c|c|c|}
\hline Indicadores & Pesos & $\begin{array}{l}\text { nota média } \\
\text { dos } \\
\text { residentes }\end{array}$ & $\begin{array}{l}\text { nota } \\
\text { média } \\
\text { dos } \\
\text { visitantes }\end{array}$ & $\begin{array}{l}\text { media } \\
\text { geral } \\
(\bar{I})\end{array}$ & $\begin{array}{l}\text { Índice } \\
\left(\mathbf{p} . \bar{I}_{\mathbf{x} 1 / k)}\right.\end{array}$ \\
\hline X2 - Patrimônio arquitetônico & 0,0310 & 3,1 & 3,26 & 3,18 & 0,0197 \\
\hline X3 - Artesanato local & 0,0442 & 3,55 & 3,15 & 3,35 & 0,0296 \\
\hline X4 - Manifestações populares & 0,0474 & 2,77 & 1,92 & 2,35 & 0,0222 \\
\hline X5 - Gastronomia local & 0,0313 & 3,81 & 3,86 & 3,84 & 0,0240 \\
\hline X7 - Passeios oferecidos & 0,0388 & 3,39 & 3,25 & 3,32 & 0,0258 \\
\hline X8 - Informação turística & 0,0324 & 2,67 & 3,3 & 2,99 & 0,0193 \\
\hline X9 - Guia turístico & 0,0402 & 2,36 & 2,38 & 2,37 & 0,0191 \\
\hline X11 - Meios de hospedagem & 0,0421 & 3,43 & 3,63 & 3,53 & 0,0297 \\
\hline X12 - Diversão noturna & 0,0193 & 2,19 & 3,06 & 2,63 & 0,0101 \\
\hline X13 - Receptivo turístico & 0,0507 & 2,62 & 2,45 & 2,54 & 0,0257 \\
\hline
\end{tabular}


X16 - Abastecimento de água

X17 - Pavimentação

X18 - Sinalização urbana

X22 - Transporte marítimo

X23 - Terminal marítimo

X27 - Valor da diária em hotel

X28 - Preço da alimentação

X30 - Coleta de lixo

X31 - Limpeza dos banheiros das barracas

X32 - Distribuição da rede de esgoto

X33 - Limpeza dos barcos

\begin{tabular}{|c|c|c|c|c|}
\hline 0,0268 & 2,43 & 2,45 & 2,44 & 0,0131 \\
\hline 0,0529 & 2,43 & 2,49 & 2,46 & 0,0260 \\
\hline 0,0448 & 2,32 & 2,26 & 2,29 & 0,0205 \\
\hline 0,1038 & 3,95 & 3,21 & 3,58 & 0,0743 \\
\hline 0,0934 & 3,06 & 2,83 & 2,95 & 0,0550 \\
\hline 0,0385 & 2,58 & 2,17 & 2,38 & 0,0183 \\
\hline 0,0409 & 2,72 & 2,67 & 2,70 & 0,0220 \\
\hline 0,0498 & 1,96 & 2,8 & 2,38 & 0,0237 \\
\hline 0,0355 & 2,09 & 2,39 & 2,24 & 0,0159 \\
\hline 0,0415 & 1,31 & 1,87 & 1,59 & 0,0132 \\
\hline 0,0948 & 3,58 & 2,86 & 3,22 & 0,0611 \\
\hline 1,00 & & & & 0,5684 \\
\hline
\end{tabular}

Fonte: dados da pesquisa

Após os cálculos a partir da Equação 01 foi possível obter o índice para a Baía de Camamu, comunidade de Barra Grande, que resultou em um valor de 0,57. Procurando dimensionar o índice em termos de sua explicabilidade das condições da oferta turística local, foi criada uma escala intervalar com cinco estágios possíveis tendo-se como base as escalas de notas atribuídas aos componentes, ou seja, como o índice alcança o máximo de 1,00, tal valor foi dividido em cinco estágios $(1,00 / 5)$ sendo que o menor corresponde aos valores em um intervalo de 0,00 a 0,20 o que equivale a nota 1 e assim sucessivamente, conforme apresentados no Quadro 2. 
Quadro 2: Escala intervalar do índice de adequação da oferta turística local e seus estágios

\begin{tabular}{|l|l|}
\hline $\begin{array}{l}\text { Escala intervalar do índice de adequação da Oferta } \\
\text { turística local }\end{array}$ & Classificação \\
\hline $0,00 \leq$ (índice) $\leq 0,20$ & Oferta Turística Local não adequada \\
\hline $0,20<$ (índice) $\leq 0,40$ & Adequação regular da Oferta Turística Local \\
\hline $0,40<$ (índice) $\leq 0,60$ & Adequação razoável da Oferta turística Local \\
\hline $0,60<$ (índice) $\leq 0,80$ & Boa adequação da Oferta Turística local \\
\hline $0,80<$ (índice) $\leq 1,00$ & Ótima adequação da Oferta turística Local \\
\hline
\end{tabular}

Fonte: Elaboração do autor

Com base na classificação exposta no quadro 3 e no valor obtido para o índice, conclui-se que as condições locais para o turismo encontra-se em um estágio intermediário indicando um certo grau de carência no atendimento à satisfação dos visitantes e dos moradores. $\mathrm{O}$ índice, a despeito de não levar em conta os atrativos naturais, principal motivo da viagem à Baía de Camamu, reflete em seu valor a condição na qual se encontra a localidade nos mais variados aspectos da sua Oferta Turística.

\section{Considerações Finais}

O processo de desenvolvimento local requer a integração e cooperação dos grupos de interesse nos mais variados aspectos da dinâmica de uma localidade. Deve haver uma prática e uma vontade comum a todos aqueles que desejam promover um desenvolvimento assentado nas potencialidades próprias do lugar, fugindo à regra de um modelo que impõe soluções globais, uniformizador e massificador de culturas. Desenvolvimento local pressupõe endogenia e acima de tudo valorização das características locais e condições reais para a participação e envolvimento da comunidade na condução do planejamento e de políticas voltadas ao incremento econômico e bem estar socioambiental.

O turismo, a despeito da sua índole mercadológica e massificadora, pode se reverter em um vetor de desenvolvimento quando firmado em bases locais impulsionado pela diversidade e 
com seus componentes da oferta turística conformados às expectativas do visitante e, sobretudo às da comunidade receptora. Nesta perspectiva é que este trabalho objetivou avaliar a oferta turística na Baía de Camamu não só sob a ótica do visitante, mas também, e, principalmente, a partir dos residentes.

A avaliação da oferta turística na Baía de Camamu foi realizada especificamente e intencionalmente na comunidade de Barra Grande, para onde converge o fluxo turístico naquele espaço. A maioria dos indicadores avaliados por visitantes e moradores foram pontuados com notas baixas o que mostra a fragilidade desses componentes para a adequação da oferta turística, merecendo no mínimo uma atenção e discussões em torno de possíveis ações que visem à mitigação de tais problemas. A precariedade desses componentes revela uma fragilidade para o destino e compromete substancialmente a experiência da visitação, principalmente quando se pensa em um destino turístico em que seus espaços são acessíveis a todos os turistas e comuns aos moradores possibilitando assim maior interatividade entre os dois grupos.

Alguns fatores mostram condições razoáveis para atender ao visitante e ao residente, a exemplo do Fator 1 (Experiência no translado marítimo pela Baía de Camamu) que contempla alguns dos principais componentes e significando o primeiro contato do visitante com os atrativos do local.

Os componentes em condições mais críticas e que requerem intervenções mais urgentes fazem parte do Fator 5 ( Condições sanitárias e ambientais do local), merecendo uma maior atenção por parte do poder público local e dos proprietários das barracas de praia. É impossível se pensar em desenvolvimento da atividade turística e até mesmo em bem estar dos visitantes e dos residentes com a manutenção dessa realidade. Tais componentes deverão ter prioridade para ações que visem o desenvolvimento local.

Os outros Fatores apresentam componentes em condições razoáveis com necessidade de melhoria na sua qualidade em termos de infraestrutura e prestação de serviço. Uma visão geral pode ser obtida a partir do índice de adequação da Oferta Turística Local, que, tenta refletir o estado atual da oferta turística e sua adequação para o desenvolvimento local. $\mathrm{O}$ índice revela uma condição não favorável e suscita ações para a melhoria de todos os 
componentes objetivando uma atividade turística que satisfaça às expectativas dos visitantes e ao mesmo tempo seja do interesse da comunidade.

Sobre esse aspecto vale destacar os indicadores "Serviços bancários", que não foi associado a nenhum dos fatores extraídos a partir da Análise Fatorial realizada, e o indicador "Pavimentação", os quais mesmo obtendo avaliações não satisfatórias pela maioria dos visitantes e dos moradores foram defendidos por parte daqueles dois grupos de entrevistados quanto a manutenção do estado atual daqueles componentes. Será que é do interesse da comunidade ter a difusão de caixas eletrônicos ou agências bancárias? Uma resposta deve ser obtida através de um amplo debate com todos os envolvidos. É realmente necessário pavimentar as ruas como desejam alguns turistas? Isso não causaria uma descaracterização da paisagem própria do lugar como sugerem alguns dos moradores? Provocam-se tais questionamentos no sentido de chamar a atenção para o fato de que nem sempre medidas e intervenções verticalizadas, colocadas em prática no intuito de atender ao turista, são medidas que retratam os anseios da comunidade e a forma como ela espera que seja conduzido o turismo local.

Assim, é importante reconhecer que apesar do atrativo natural ainda ser o mais importante componente quando da decisão de viajar para a Baía de Camamu, existem problemas e fragilidades em torno dos outros componentes que comprometem a qualidade da visitação e indicam também condições infraestruturais inapropriadas para a comunidade local.

É chegado o tempo, ainda que tardiamente, de (re)pensar a configuração e a inserção da Baía de Camamu enquanto possível produto turístico no cenário do turismo local, nacional e global e o modelo de oferta turística que se pretende ter. Em razão das características do destino, não é difícil argumentar em defesa de um modelo que privilegie a busca pelo desenvolvimento local.

Contribuições futuras poderão avançar na busca de repostas àquilo que não foi contemplado neste trabalho em virtude das limitações de tempo, recursos e em virtude do seu escopo. $\mathrm{O}$ caminho foi iniciado, coube a esta pesquisa apresentar os fatores determinantes e impeditivos ao desenvolvimento da atividade turística na Baía de Camamu, caberá ao futuro nos mostrar em que medida o poder público, comunidade, empresários, todos os grupos de interesse se 
moveram para dá forma a um destino turístico avaliado como socialmente inclusivo, viável e, sobretudo, único.

\section{Referências}

CERQUEIRA, Cristiane Aparecida de. Análise estrutural do turismo do município de Ilhéus (Ba). Piracicaba, SP, 2002. 167f. Dissertação (Mestrado) - Universidade de São Paulo. Escola Superior de Agricultura Luiz de Queiroz.

CERQUEIRA, Cristiane A.; FREIRE, Carla R. F. O turismo do município de Itacaré (BA): uma aplicação da Análise Fatorial para estimar os fatores determinantes da oferta turística na alta estação do ano de 2006. In: ENCONTRO DE ECONOMIA BAIANA, 4., Salvador. Anais... Salvador: UFBA, 2008.

CORIOLANO, Luzia N. M. T. Os limites do desenvolvimento e do turismo. Pasos - Revista de turismo y patrimonio cultural, San Cristóbal de La laguna-Tenerife, vol.1, n.2, p. 161-171, 2003. Disponível em:

<http://www.pasosonline.org/Publicados/1203/PS040603.pdf>. Acesso em: 25 mai. 2010.

CORIOLANO, Luzia Neide Menezes Teixeira. Turismo e meio ambiente: a (in)sustentabilidade em questão. In: ENCONTRO NACIONAL DE TURISMO COM BASE LOCAL, 9., 2005, Recife. Anais... Recife: UFPE, 2005.

COSTA, C.A.G. O uso de agrotóxicos na agricultura irrigada na Bacia do Baixo Jaguaribe-CE. Monografia de graduação em Agronomia; Universidade Federal do Ceará, Fortaleza, 2006.76f.

FRANCO, Augusto de. Porque precisamos de desenvolvimento local integrado e sustentável. 4 ed. Brasília: Instituto de Política, 2001.

FRIEDMAN, Jonathan. Ser no mundo: globalização e localização. In: FEATHERSTONE, M. Cultura global: nacionalismo, globalização e modernidade. 3. ed. Petrópolis: Vozes, 1999.

GRÜNEWALD, Rodrigo de Azeredo. Turismo e etnicidade. Revista Horizontes Antropológicos. Porto Alegre, ano 9, n.20, p. 141-159, Out. 2003.

HAIR Jr, Joseph F et al. Fundamentos de pesquisa em Administração. Porto Alegre: Artmed Bookman, 2003.

. Analise multivariada de dados. Porto Alegre: Artmed Bookman, 2007.

IGNARRA, Luiz Renato. . Fundamentos do turismo. 2. ed. rev. e ampl. São Paulo: Pioneira Thomson Learning, 2003.

IRVING, M. A. Turismo, ética e educação ambiental - novos paradigmas em planejamento. In: IRVING, M.A.; AZEVEDO, J. (Org.). Turismo: o desafio da sustentabilidade. São Paulo: Futura, 2002, p. 17-34.

LOPES, Fernando B. et al. Proposta de um índice de sustentabilidade do Perímetro Irrigado Baixo Acaraú, Ceará, Brasil. Revista Ciência Agronômica, Fortaleza, v.40, n.2, p.185-193, abr-jun, 2009.

MAROCO, João. Análise Estatística com utilização do SPSS. 2.ed. Lisboa: Edições Sílabo, 2003. 
MALHOTRA, N. K. Pesquisa em Marketing. Uma orientação aplicada. Porto Alegre: Bookman, 2001.

MENDONÇA, T.C. de M; IRVING, M. de A. Realidade e desafios na construção de projetos turísticos de base comunitária. In: TREVIZAN, S.D.P (Org.). Comunidades sustentáveis a partir do turismo com base local. Ilhéus: Editus, 2006.

MINISTÉRIO DO TURISMO. Dados e fatos - estudos e pesquisas. Disponível em: < http://www.turismo.gov.br>. Acesso em : 30 set. 2008.

Turismo no Brasil - 2007/2010. Brasília. 2006. Disponível em: < http://www.turismo.gov.br>. Acesso em: 30 set. 2008.

. Turismo no Brasil: análise e tendências. Baueri: Manole, 2002.

MONIZ, Ana Isabel. D. S.A. A sustentabilidade do turismo em ilhas de pequena dimensão: o caso dos açores. 2006. Tese (Doutorado em Desenvolvimento Econômico e Social e Economia Pública) Universidade dos Açores, Ponta Delgada, 2006.

PAULA, Juarez de. Desenvolvimento e gestão compartilhada. In: SILVEIRA, Caio; REIS, Liliane (Orgs.). Desenvolvimento local: dinâmica e estratégias. Rio de Janeiro: DLIS, 2001.

SHARMA, S. Applied Multivariate Techniques. New York: John Wiley \& Sons, 1996.

SILVEIRA, S. S.; ANDRADE, E. M. Análise de componentes principais na investigação da estrutura multivariada da evapotranspiração. Revista Engenharia Agrícola, v. 22, n. 02, p. 174-177, 2002.

SOUZA, M. J. Como pode o turismo contribuir para o desenvolvimento local. In: RODRIGUES, A. B. Turismo e desenvolvimento local. 2. ed. São Paulo: HUCITEC, 1999.

TEIXEIRA, A. Turismo sustentável: mito ou realidade? Conferência Latino Americana de Meio Ambiente e Responsabilidade Social. Disponível em: <www.ecolatina.com.br >. Acesso em 01 set. 2006.

TREVIZAN, S.D.P (Org.). Comunidades sustentáveis a partir do turismo com base local. Ilhéus: Editus, 2006.

VICINI, Lorena; SOUZA,Adriano Mendonça. Análise multivariada da teoria à prática. Santa Maria: UFSM,CCNE, 2005.

Recebido em: 04/04/2012 ( $1^{\text {a }}$ versão) 31/07/2012 ( $2^{\mathrm{a}}$ versão)

Aprovado em: 08/08/2012 